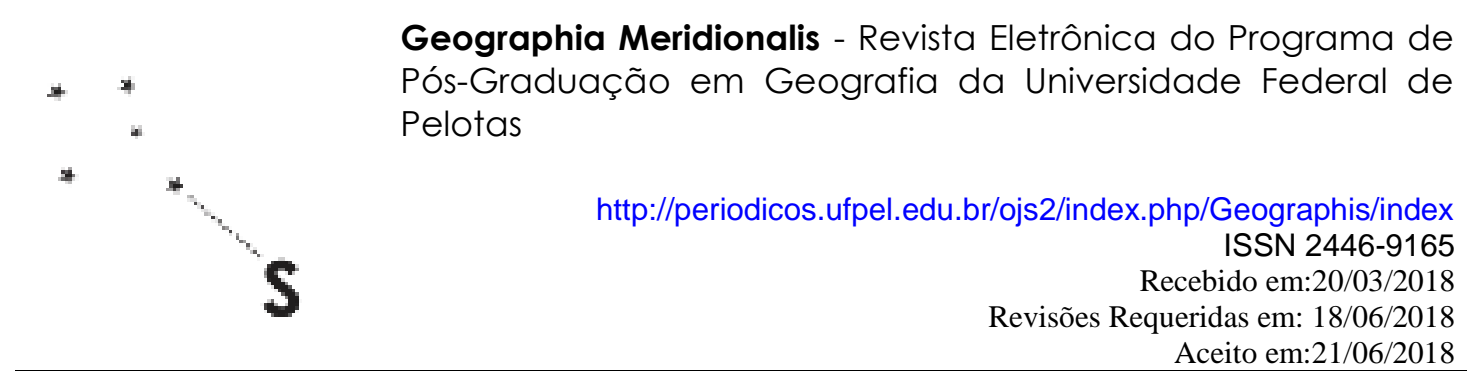

\title{
UMA REFLEXÃO CRÍTICA SOBRE OS CONCEITOS E PRÁTICAS DA GEOCONSERVAÇÃO \\ A CRITICAL REFLECTION ON THE CONCEPTS AND PRACTICES OF GEOCONSERVATION
}

\author{
André Weissheimer de Borba \\ Universidade Federal de Santa Maria \\ Professor Adjunto \\ awborba.geo@gmail.com \\ Jaciele Carine Sell \\ Universidade Federal de Santa Maria \\ Pró-reitoria de Extensão \\ jacics@gmail.com
}

\section{RESUMO}

Este trabalho traz uma série de constatações e provocações sobre os conceitos e práticas adotadas na pesquisa e na aplicação da geoconservação, área emergente das geociências. São revisados e discutidos diversos trabalhos anteriores versando sobre os conceitos de geodiversidade, geopatrimônio, geoturismo e geoparques, bem como sobre a filosofia subjacente à própria geoconservação. A necessária contribuição da ciência geográfica, as relações entre geodiversidade e paisagem, bem como a importância do conceito de território para os geoparques recebem uma atenção especial. As metodologias de avaliação quantitativa do geopatrimônio também são focalizadas a partir de uma visão crítica, no sentido de evitar critérios elitistas ou com viés demasiadamente urbano. Todas essas discussões objetivam promover uma geoconservação social e ambientalmente responsável, que respeite seus objetivos primordiais: a redução das desigualdades regionais e o resgate de áreas rurais pedregosas, marginalizadas e economicamente deprimidas, por meio da conservação, da educação e do turismo, com valorização de suas feições geológicas e geomorfológicas.

Palavras-chave: Geodiversidade; Geopatrimônio; Geoturismo; Geoparques. 


\begin{abstract}
This paper brings a critical view on the concepts and practices employed in the research and application of geoconservation as an emerging area of geoscience. The terms geodiversity, geoheritage, geotourism and geoparks are reviewed and discussed, as well as the very philosophical bases of geoconservation. Special attention is drawn to the necessary contribution of the geographical science, the relationships between geodiversity and landscape, and the relevance of the concept of territory for the geopark strategy. Methodologies of quantitative assessment of geoheritage are also focused from a critical point of view, avoiding elitist or overly urban-biased criteria. The overall discussion aims at promoting a socially and environmentally responsible geoconservation, respecting its primordial goals: regional inequality reduction and revitalization of hilly, marginal, economic depressed rural areas through conservation, education and tourism, with appreciation of their geological and geomorphological features.
\end{abstract}

Keywords: Geodiversity; Geoheritage; Geotourism; Geoparks. 


\section{1 - Introdução}

A geoconservação, enquanto nova e emergente área das geociências (HENRIQUES et al., 2011), engloba conceitos, metodologias e iniciativas que já contam com cerca de 30 anos de amadurecimento, desde a divulgação da carta de Digne-les-Bains sobre a proteção dos direitos à memória da Terra. Nessas três décadas, os conceitos de geodiversidade (STANLEY, 2000; GRAY, 2004; PANIZZA, 2009; RUBAN, 2010), geopatrimônio (RODRIGUES e FONSECA, 2008; BORBA, 2011), geoturismo (HOSE, 1995; RUCHKYS, 2007; CARCAVILLA-URQUÍ, 2012) e geoeducação (MAKSOUD et al., 2014; MOURA-FÉ, 2016), bem como as iniciativas e estratégias relacionadas, têm progressivamente ocupado mais espaço na literatura geocientífica brasileira e internacional. Tais conceitos e práticas estão na base, também, da certificação de territórios como Geoparques Mundiais (ou Global Geoparks), um programa hoje efetivamente vinculado à estrutura da UNESCO (ZOUROS, 2004; McKEEVER e ZOUROS, 2005; UNESCO, 2016; HENRIQUES e BRILHA, 2017).

A interpretação e a utilização dos termos e ferramentas da geoconservação, contudo, são diversas, desuniformes e, por vezes, discrepantes, seja no meio acadêmico ou no âmbito profissional das geociências, no Brasil e no mundo. Percebem-se diferentes visões e abordagens sobre geodiversidade, geopatrimônio, geoturismo, geoeducação e geoparques, que se refletem nas opções por distintas metodologias de inventário, avaliação quantitativa e iniciativas (práticas ou legais) de geoconservação. Essas perspectivas variam de acordo com os perfis e o background de pesquisadores e profissionais, com os interesses e o know-how das instituições ou indivíduos envolvidos, com as características e potencialidades da região de atuação e com a própria natureza do geopatrimônio, entre outros fatores. Muitas vezes, nesse "jogo" de opções e interesses, os conceitos e estratégias utilizados colidem frontalmente com uma das filosofias iniciais da geoconservação: a tentativa de resgate socioeconômico de áreas rurais pedregosas, de relevo acidentado, marginalizadas pelo modelo econômico vigente, sofrendo com êxodo rural, envelhecimento e perda de população; um resgate produzido por meio da valorização e uso sustentável das feições destacadas da geodiversidade, sobretudo mediante educação e turismo, com forte apoio nas comunidades locais (McKEEVER e ZOUROS, 2005). 
Nesse contexto, o presente trabalho tem por objetivo apresentar uma reflexão crítica sobre os conceitos utilizados pela geoconservação, incluindo a abrangência da geodiversidade e seu correto posicionamento frente a distintas categorias de análise da ciência geográfica, especialmente paisagem e território. Ao mesmo tempo, avaliam-se de forma crítica as metodologias de inventário e análise quantitativa de elementos da geodiversidade, a adoção irrefletida de alguns parâmetros de quantificação e a construção do conceito de patrimônio para a geoconservação, bem como algumas iniciativas e estratégias empregadas por instituições brasileiras e estrangeiras. Espera-se, com esta contribuição, provocar novas reflexões e um debate crítico, criterioso e contextualizado, no Brasil e em outros países de língua portuguesa, sobre as virtudes, as falhas e a necessária qualificação da geoconservação enquanto nova vertente das geociências e enquanto prática socioambiental.

\section{2 - Geodiversidade: significado, abrangência e relação com a paisagem}

O termo geodiversidade, uma contração de "diversidade geológica e geomorfológica", surgiu no início dos anos 1990 como uma analogia ao termo biodiversidade (GRAY, 2004; 2008), como um manifesto no sentido de que os materiais e processos abióticos da natureza tivessem, no campo da conservação ambiental, tanta atenção quanto a diversidade dos seres vivos. Gray (2004, p. 8, tradução nossa) apresentou um conceito bastante abrangente para a geodiversidade: “(...) variedade natural de feições geológicas (minerais, rochas, fósseis), geomorfológicas (formas de relevo e processos ativos) e de solo, incluindo suas assembleias, relações, propriedades, interpretações e sistemas”.

Examinando detalhadamente o conceito proposto por Gray (2004), pode-se chegar a algumas elaborações e exemplos. Entre as "feições geológicas”, destacam-se as rochas, seus componentes e suas estruturas de gênese, deformação e alteração. Uma sucessão como a das Guaritas de Caçapava do Sul (Fig. 1), por exemplo, de camadas de espessura variável de arenitos, arenitos conglomeráticos e conglomerados com estratificação cruzada, fraturados e intemperizados possui, no mínimo, os seguintes elementos da geodiversidade: (a) os grãos de quartzo, feldspato e minerais opacos da matriz sedimentar; (b) o cimento calcítico que proporciona a coesão da rocha; (c) os seixos e blocos arredondados, de diversas composições e proveniências, dispersos na matriz; (d) a rocha sedimentar em si, que engloba todos os elementos anteriores, mas também é um elemento 
da geodiversidade, com sua textura, coesão, coloração avermelhada e aspereza próprias; (e) a geometria das camadas e suas espessuras; (f) as estratificações cruzadas; e (g) as fraturas que afetam a rocha. Cada uma dessas feições ou elementos da geodiversidade possui um significado em termos de história evolutiva para essas rochas.

Figura 1. Elementos da geodiversidade das Guaritas de Caçapava do Sul: (A) alternância de camadas tabulares e lenticulares de arenitos de coloração avermelhada e conglomerados, todas de origem fluvial; (B) fragmentos arredondados, tamanho bloco, imersos em uma matriz arenosa e granular, registrando o transporte em meio aquoso dos sedimentos, durante a formação dos depósitos fluviais.
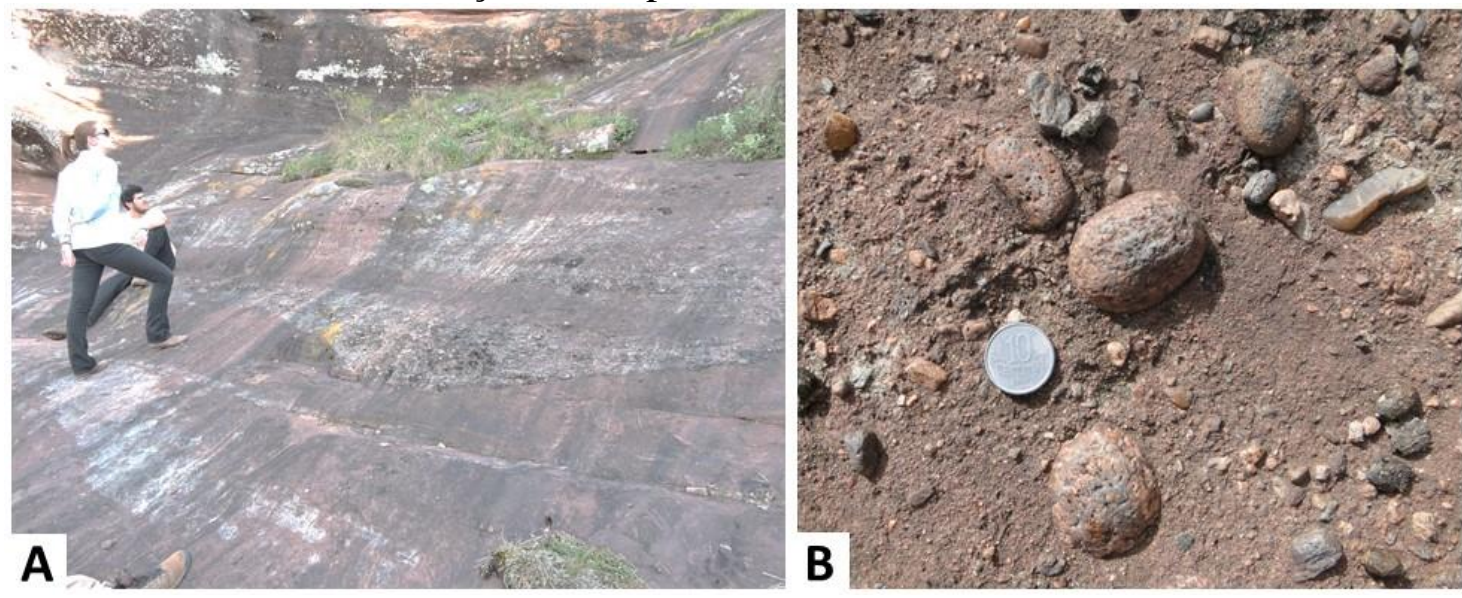

Fonte: Elaborado pelos autores, a partir de fotografias próprias.

Com relação às "feições geomorfológicas e de solo", relacionadas à exposição dessas rochas à superfície e aos fatores climáticos, seguindo o mesmo exemplo das Guaritas (Fig. 2), somam-se a essa geodiversidade outros elementos: (h) cerros tabulares e ruiniformes; (i) janelas de desgaste hídrico/eólico; (j) panelas e marmitas de abrasão hídrica; (1) coluviões e aluviões relacionados a esses processos; e (m) os horizontes de alteração de rocha e pedogênese. Merece destaque também a parte final do conceito de Gray (2004, tradução nossa), que cita "assembleias, relações, propriedades (...) e sistemas". Paragêneses metamórficas, assembleias de minerais pesados, faunas e floras fósseis, ou ainda associações de fácies sedimentares são apenas alguns exemplos de conjuntos de elementos da geodiversidade que podem significar mais (ou, pelo menos, ter implicações de maior abrangência) do que ocorrências isoladas de um de seus componentes. Relações de corte, de conteúdo/continente, discordâncias ou hiatos de não-deposição, na abordagem da estratigrafia, possuem significado próprio e altamente relevante, independentemente dos tipos de camadas ou objetos envolvidos nessas relações. As propriedades dos minerais e das rochas possuem grande importância para a sociedade: 
por exemplo, a característica do mineral calcita (carbonato de cálcio, $\mathrm{CaCO}_{3}$ ) de efervescer quando em contato com ácidos fracos tem grande importância na compreensão, na prevenção e no tratamento de problemas relacionados à ação das águas subterrâneas e sua influência sobre acidentes geotécnicos em terrenos carbonáticos, bem como no estudo da conservação de monumentos pétreos esculpidos em mármores ou calcários. Por fim, ao citar "sistemas", é possível que Gray (2004) se reportasse, por exemplo, aos sistemas deposicionais (aluviais, fluviais, deltaicos, eólicos, marinhos ou glaciais, entre outros) do presente e do passado, responsáveis pelo preenchimento das bacias sedimentares.

Por fim, o conceito proposto por Gray (2004) refere-se às "interpretações" sobre as feições geológicas e geomorfológicas, e esse é um ponto crucial, pois salienta a importância da geologia e da geomorfologia como uma "viagem no tempo". Os arenitos conglomeráticos das Guaritas refletem a atuação, no Paleozoico inferior (500 milhões de anos), de grandes canais fluviais entrelaçados, de carga arenosa, que corriam de norte para sul, depositando ali sua carga sedimentar (PAIM et al., 2000), posteriormente compactada e transformada em rochas. Essa interpretação da gênese das rochas, incluindo a visualização mental daquele ambiente intangível no tempo profundo (Fig. 3), também pode ser considerada parte do conceito de geodiversidade, pois denota processos terrestres (físicos, abióticos) que efetivamente ocorreram no passado, e cuja existência é comprovada pelo registro geológico material que se verifica na atualidade. 
Figura 2. Elementos da geodiversidade de cunho geomorfológico, relacionados ao progressivo desgaste das rochas em seu processo de exposição à superfície e aos agentes do intemperismo: (A) cerros ruiniformes que compõem a vista mais clássica do geomonumento das Pedras das Guaritas; (B) janelas de erosão e abrasão hídrica e eólica escavadas nos arenitos das Guaritas; (C) marmitas formadas pela abrasão de blocos desprendidos sobre a sua própria rocha matriz, durante fluxos mais intensos de canais fluviais efêmeros componentes da bacia do arroio Passo dos Negros, nos domínios das Guaritas de Caçapava do Sul.

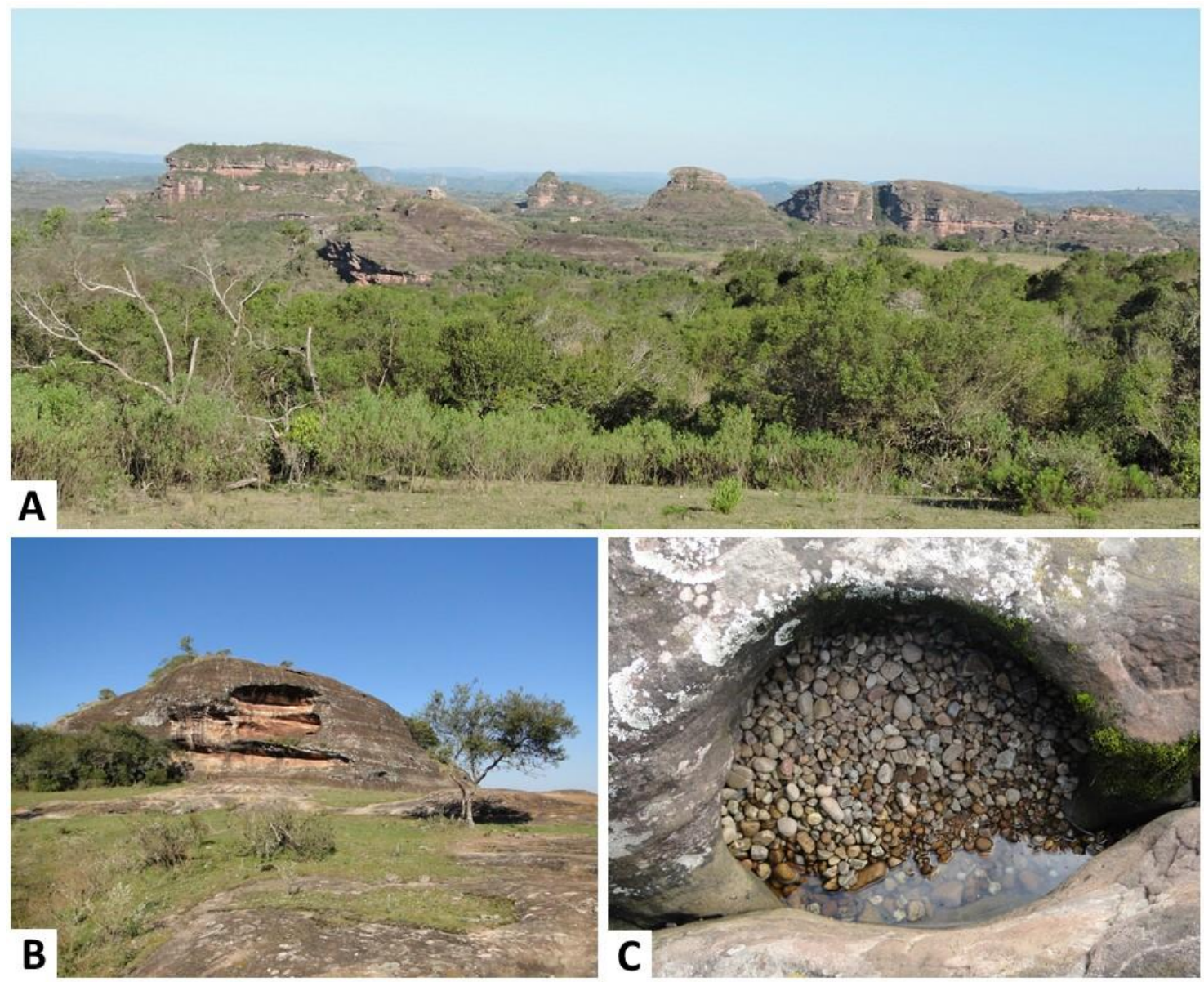

Fonte: Elaborado pelos autores, a partir de fotografias próprias. 
Figura 3. A interpretação dos ambientes pretéritos formadores das rochas que afloram na superfície da Terra representa um dos componentes da geodiversidade. Por exemplo, as camadas fluviais das Guaritas de Caçapava do Sul (A) registram uma história geológica que envolve a atividade, há 500 milhões de anos atrás, de uma ampla planície fluvial composta por canais entrelaçados, ambiente semelhante a vários exemplos atuais (B), como o do rio Desaguadero, em La Rioja (Argentina).

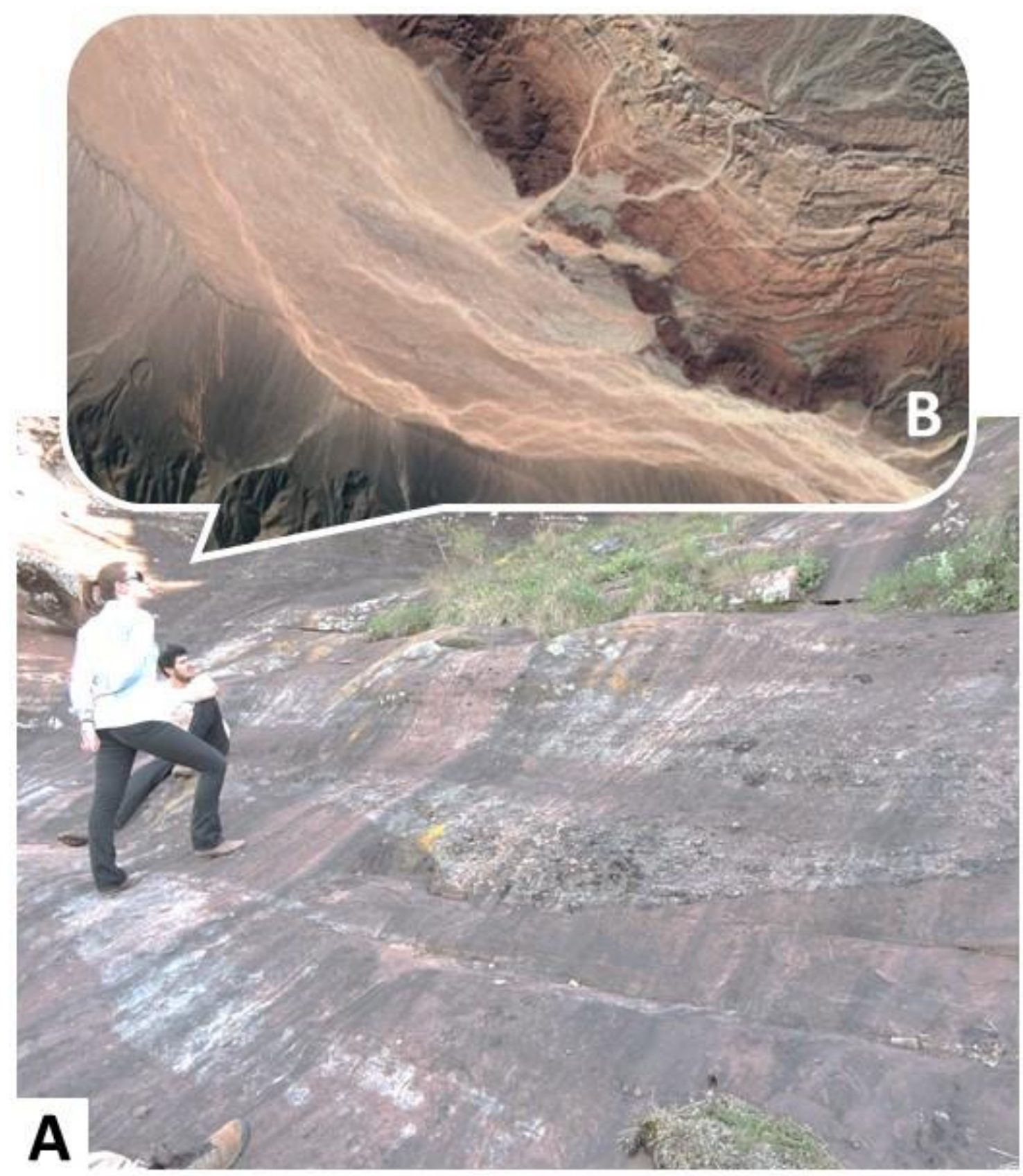

Fonte: Elaborado pelos autores. A imagem em (A) é uma fotografia própria dos autores. A imagem utilizada para inserção no "balão" (B) é uma imagem de satélite (meramente ilustrativa) extraída do site/programa GoogleEarth®, que ilustra o sistema fluvial entrelaçado do rio Desaguadero, próximo a Vinchina, na Província de La Rioja, região andina da Argentina. 
Outra formulação importante para o conceito de geodiversidade e para a discussão que se pretende aqui, e ainda anterior àquela detalhada acima, foi trabalhada por Stanley (2000, p. 15, tradução nossa), focalizando mais os processos formadores: “(...) a variedade de ambientes, fenômenos e processos geológicos que produzem paisagens, rochas, minerais, solos e outros depósitos superficiais formadores do arcabouço que sustenta a vida na Terra". A presença do termo "paisagens" (no original em inglês, landscapes) nesse conceito tem levado, no Brasil e em outros países de língua portuguesa, a algumas interpretações equivocadas de que a paisagem seria, ela própria, um elemento da geodiversidade. A origem desse equívoco pode estar também no livro de Brilha (2005), autor que, ao reproduzir o conceito de geoconservação elaborado na Tasmânia por Sharples (2002), traduz o termo original inglês landform (forma de relevo) por "formas de paisagem" (BRILHA, 2005, p. 51), equívoco que segue sendo repetido por autores brasileiros. Mantesso-Neto (2010), por exemplo, em resumo de apresentação oral realizada no $45^{\circ}$ Congresso Brasileiro de Geologia, em Belém/PA, conceitua geodiversidade como “(...) variedade de paisagens, rochas, minerais, fósseis, solos, etc. (...)". Enquanto isso, Lopes \& Araújo (2011, p. 67) chegam a afirmar que “(...) a geodiversidade é o resultado dos processos interativos entre a paisagem, a fauna, a flora e a nossa cultura".

Para discutir tais equívocos, é necessário revisar brevemente a perspectiva da geografia sobre a paisagem, uma das principais categorias de análise da ciência geográfica, juntamente com espaço, lugar, região e território. Para Bertrand (1972, p. 2), a paisagem é “(...) uma determinada porção do espaço, resultado da combinação dinâmica, portanto instável, de elementos físicos, biológicos e antrópicos que, reagindo dialeticamente uns sobre os outros, fazem da paisagem um conjunto único e indissociável, em perpétua evolução". Está claro que os "elementos físicos" de que trata esse conceito são os elementos geológicos, geomorfológicos e pedológicos, bem como seus processos genéticos e atuantes, ou seja, a geodiversidade. A paisagem (Fig. 4), portanto, longe de ser apenas um aspecto visual ou uma escala de trabalho, seria a combinação sistêmica (e.g. SOTCHAVA, 1977; ROMERO e JIMÉNEZ, 2002) de elementos da geodiversidade, elementos da biodiversidade e elementos da diversidade cultural, ou seja, as marcas transformadoras da ação humana. Assim, conforme demonstra a figura 4: (a) uma zona urbana ou um empreendimento agropecuário representam paisagens nas quais o elemento 
antrópico/social/humano/cultural é mais marcante; enquanto isso, (b) uma floresta, uma grande extensão de campo nativo ou um banhado são paisagens em que o elemento biótico é mais relevante; por fim, (c) uma zona vulcânica, um deserto ou uma geleira constituem paisagens onde a geodiversidade, como substrato físico ou processo ativo, é o fator dominante. A grande maioria das paisagens contempla esses três elementos em diferentes proporções, cada um deles transformando-se e afetando os demais em sua escala temporal de atuação. Dessa forma, a paisagem não pode ser considerada um elemento da geodiversidade; pelo contrário, a geodiversidade é que constitui um dos elementos estruturadores da paisagem.

Figura 4. Representação esquemática, em diagrama triangular, do conceito de "paisagem" para a geografia, formada pela interação de elementos da geodiversidade (GEO), da biodiversidade (BIO) e da diversidade cultural ou ação humana (elemento HUMANO) sobre os ambientes naturais. No interior do triângulo, próximo aos vértices, alguns exemplos de paisagens onde um desses componentes predomina sobre os demais.

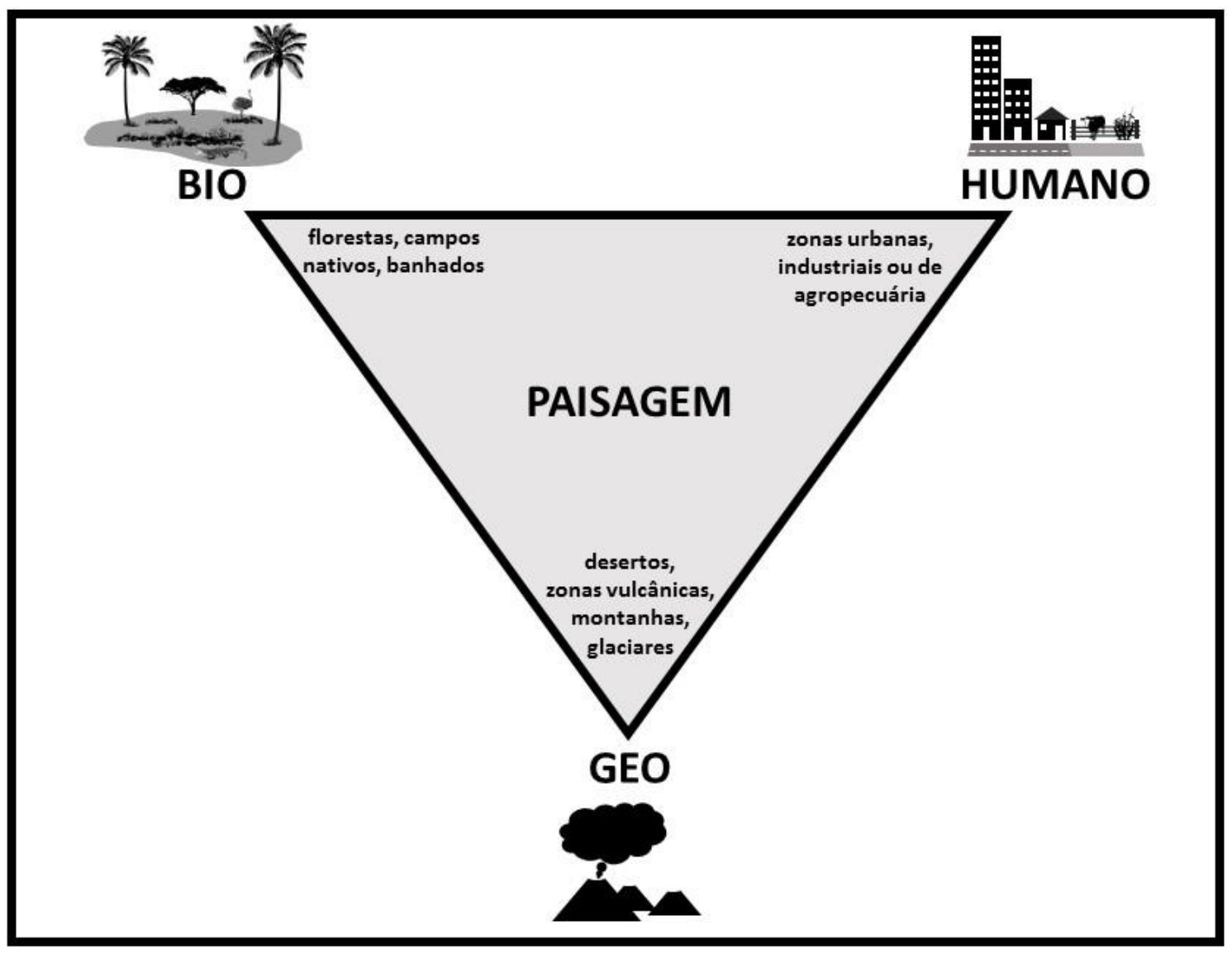

Fonte: Elaborado pelos autores. 


\section{3 - Geopatrimônio ou patrimônio geológico: memória da Terra ou patrimônio dos geólogos?}

A geodiversidade, conforme detalhado acima, constitui a totalidade dos materiais formados, dos processos ocorridos e das relações estabelecidas, ao longo do tempo geológico, pela natureza abiótica; o somatório de todos os elementos da geodiversidade. Tais elementos, estando in situ ou ex situ, guardam suas propriedades e constituem uma memória de sua história evolutiva. A esses elementos são atribuídos, pela ciência e pela sociedade, uma série de valores (GRAY, 2004; BRILHA, 2005): (a) intrínseco ou valor de existência, independente de avaliação humana; (b) estético, de cunho subjetivo, relacionado à noção de beleza cênica; (c) cultural, vinculado à toponímia, à história, ao uso tradicional dos materiais e a todas as demais manifestações culturais; (d) funcional/ecológico, relacionado à importância da geodiversidade para a estruturação de habitat naturais e de sua sobrevivência; (e) funcional/utilitário, vinculado ao papel da geodiversidade in situ como substrato, suporte, reservatório ou repositório de substâncias, elementos ou obras de relevância para a humanidade; (f) científico, associado ao conhecimento acumulado pelo meio acadêmico sobre a geodiversidade; (g) educativo, vinculado à transmissão desse conhecimento nas diferentes fases do ensino/aprendizagem; e (h) econômico, voltado à visão do mercado e do setor mineral dos materiais da geodiversidade (ex situ) como "recursos minerais" destinados à extração e à indústria da transformação.

O aproveitamento econômico, pelo setor mineral, dos materiais da geodiversidade leva, em grande parte, a seu consumo e destruição pela indústria, degradando o ambiente e inviabilizando ou inutilizando outros valores daquele material ou local. Outros tipos de atividades econômicas/estratégicas, como silvicultura, agricultura de precisão, urbanização, grandes obras de engenharia (barragens, rodovias) e atividades militares, entre outros, levam também à destruição ou, no mínimo, ocultação de elementos da geodiversidade (e.g. BRILHA, 2005). É exatamente da percepção e da avaliação desses riscos de degradação que se desenvolve o conceito de "patrimônio geológico": dentre o todo que é a geodiversidade, quais são aquelas ocorrências ou elementos realmente relevantes, nos valores não ligados a seu consumo/destruição? Qual é a parte da geodiversidade que deve ser protegida e valorizada por ter relevância científica, educativa, cultural, funcional/ecológica e/ou estética? 
Um dos principais objetivos da atribuição de um caráter patrimonial a determinados elementos da geodiversidade é a aproximação das geociências em relação à sociedade e, sobretudo, em relação àquelas comunidades que habitam áreas valorizadas pela academia. Um dos trabalhos mais interessantes nesse esforço de aproximação é um texto de Brilha (2004) intitulado: “a geologia, os geólogos e o manto da invisibilidade”. Naquele trabalho, o pesquisador português advoga por maior inserção dos geólogos na sociedade e na política, para remover o "manto de invisibilidade" que envolve a profissão perante a opinião pública, relacionado inclusive à terminologia geológica complicada, que deve ser traduzida. Recentemente, no entanto, o mesmo autor (BRILHA, 2016) parece voltar a vestir o referido "manto", ao preconizar que o caráter patrimonial deve ser atribuído a uma ocorrência da geodiversidade apenas quando esta possuir relevante valor científico. Segundo o referido trabalho, os locais de interesse geológico seriam, inclusive, divididos em "geossítios", quando tiverem alto valor científico, e "sítios da geodiversidade", quando seu interesse for turístico ou educativo. Esses últimos não seriam dotados de valor patrimonial.

Ou seja, na recente formulação de Brilha (2016), se uma ocorrência da geodiversidade for, do ponto de vista estético ou cultural, valorizada por toda a sociedade, mas sua geologia não for relevante do ponto de vista científico, ela não pode ser considerada patrimônio geológico. Dessa forma, percebe-se uma tendência de pensar o "patrimônio geológico" como um "patrimônio dos geólogos", o que parece muito equivocado em uma área das geociências dedicada exatamente ao diálogo com a sociedade. A noção de patrimônio é social e culturalmente construída, e sempre deve envolver a percepção que a sociedade leiga, e não apenas a academia, possui sobre determinado conteúdo, conforme proposto já por Pena-dos-Reis \& Henriques (2009). Compreende-se a necessidade de valorizar afloramentos importantes para os geocientistas, onde dados relevantes tenham sido obtidos, que muitas vezes são invisíveis para a sociedade, mas que merecem medidas de conservação e valorização. Entretanto, a priorização do valor e do olhar científico, em detrimento de outros valores ou outras percepções, não irá promover a aproximação e o diálogo com a sociedade leiga e com outras áreas do conhecimento, como as ciências biológicas e as ciências humanas, tão necessária para o sucesso da geoconservação.

O próprio termo "patrimônio geológico", conforme discutido já no trabalho de Borba (2011), pode suscitar certa resistência por parte de outros profissionais e/ou da sociedade 
em se engajar na geoconservação. Esse termo pode parecer restritivo, tanto em termos de escopo (parece englobar somente ocorrências geológicas sensu stricto) quanto em termos de competência ou atribuição (parece ser exclusivo da área de atuação do profisssional geólogo). Por isso, prefere-se aqui a utilização do termo "geopatrimônio", com o prefixo "geo" tendo exatamente a mesma abrangência do prefixo de geodiversidade, sem qualquer implicação em mudança de abordagem. Geopatrimônio, conforme proposto em Borba (2011) e neste trabalho, seria exatamente aquela parcela da geodiversidade com destacada relevância em termos de valor científico, estético, cultural, funcional/ecológico e/ou educativo. Assim, o geopatrimônio seria formado por materiais, feições, processos ou relações, deixadas como herança ou memória, pela evolução dos processos abióticos do planeta Terra, à humanidade e, em especial, às comunidades em cujo território de vida tais elementos ocorrem. É aquilo que os gregos chamam de "memória da Terra" ( $\mu \nu \eta \mu \varepsilon i ́ \alpha$ $\tau \eta \varsigma \gamma \eta ́$ ), exatamente a terminologia utilizada naquele país para patrimônio geológico ou geopatrimônio.

\section{4 - A valoração do geopatrimônio e suas distorções}

A proteção e o uso sustentável do geopatrimônio são os objetivos fundamentais da geoconservação. Para definir quais os elementos (locais ou materiais ex situ) prioritários para conservação e promoção, dentro de uma determinada estratégia e abrangência territorial, é necessário estabelecer um ranking de ocorrências mais e menos relevantes e, ao mesmo tempo, mais e menos ameaçadas. Esse é o papel das metodologias de avaliação quantitativa (ou valoração) de locais de interesse geológico. Diversas metodologias têm sido propostas ao longo das últimas décadas, e várias delas têm sido aplicadas à realidade brasileira, com maiores ou menores adaptações (BRILHA, 2005; PEREIRA, 2010; LIMA et al., 2010; FASSOULAS et al., 2012; BORBA et al., 2013; BRILHA, 2016; REVERTE e GARCIA, 2016; ROCHA et al., 2016).

Devido à influência portuguesa e à facilidade do idioma, a primeira metodologia a chegar ao Brasil foi aquela publicada por Brilha (2005), modificada de Cendrero-Uceda (2000), voltada prioritariamente ao aspecto geocientífico, com aspectos culturais e ecológicos relegados a um plano secundário. Essa tendência foi seguida e aprofundada por Lima et al. (2010) e, finalmente, por Brilha (2016), onde tais aspectos não geocientíficos só são aplicados subsidiariamente à definição dos valores de uso turístico e educativo, que não 
permitiriam a atribuição ao geossítio de um caráter patrimonial, conforme discutido acima. Esse último trabalho, de Brilha (2016), constitui a base do atual sistema de valoração de locais de interesse geológico da CPRM (Serviço Geológico do Brasil), o aplicativo GEOSSIT (ROCHA et al., 2016), e também tem sido utilizado em avaliações do geopatrimônio do litoral paulista (REVERTE e GARCIA, 2016; MUCIVUNA et al., 2017).

Uma crítica contundente deve ser feita a alguns aspectos das metodologias que evoluíram a partir do trabalho de Brilha (2005), sobretudo aos que dizem respeito aos critérios de uso e aos de necessidade de proteção. Em primeiro lugar, com relação à necessidade de proteção, o critério C3, do "interesse para a exploração mineira” (BRILHA, 2005, p. 104), atribui o valor máximo (5) para locais sem nenhum tipo de interesse mineiro, e o valor mínimo (1) para locais com "grande interesse mineiro para recursos com elevado valor unitário". A crítica a ser feita é: o valor patrimonial de um geossítio não pode ser diminuído a priori frente ao interesse do setor mineral, mas sim deve ser confrontado a esse interesse; se a região apresenta um geomonumento realmente relevante (do ponto de vista cultural, funcional/ecológico, estético, educativo e/ou científico), seus valores devem ser demonstrados para que se impeça ou discipline a extração mineral, a fim de não comprometer sua integridade, funcionalidade ou mesmo visibilidade. A preocupação com esse patrimônio deve fazer parte dos estudos de impacto ambiental e das medidas de compensação dos empreendimentos. A geoconservação não pode sucumbir à tendência (que a geologia, infelizmente, já tem) de ser um braço técnico-científico dos interesses do setor mineral. Deve, sim, enfrentar todas as ameaças ao geopatrimônio de forma coerente com sua filosofia. Felizmente, o próprio autor citado abandonou tal critério ao longo da evolução de sua pesquisa (e.g. BRILHA, 2016). Ainda assim, é importante discutir esse aspecto, uma vez que a obra citada ainda é uma das principais referências para quem se inicia na área.

Um segundo ponto importante relaciona-se com a população residente no entorno de um local de interesse geológico. O critério B6 do trabalho de Brilha (2005, p. 103) instrui o avaliador a atribuir a nota máxima (5) a locais que possuam mais de 100 mil habitantes em um raio de 25 quilômetros, o que pode ser adequado para a Europa, mas deve sofrer profundas adaptações para contextos como o brasileiro. O trabalho de Lima et al. (2010, p. 95), que propõe uma metodologia de inventário e avaliação específica para o 
patrimônio geológico brasileiro e que poderia ter efetuado tal crítica, exagera ainda mais esses números: nota 4 (máxima) para locais com mais de 1,5 milhão de habitantes em um raio de 25 quilômetros; e nota 1 (mínima) para locais entre 50 mil e 150 mil residentes no mesmo raio de abrangência. Finalmente, no trabalho de Brilha (2016), o critério F (density of population) sugere a atribuição de nota 4 (máxima) para geossítios localizados em municípios com densidade demográfica superior a 1000 habitantes por quilômetro quadrado, e de nota 1 (mínima) para sítios localizados em municípios com menos de 100 $\mathrm{hab} / \mathrm{km}^{2}$. Em qualquer um desses esquemas de avaliação quantitativa, nenhum geomonumento localizado, por exemplo, na região de Caçapava do Sul, ilustrada acima, ou na "metade sul" gaúcha em geral (cerca de $10 \mathrm{hab} / \mathrm{km}^{2}$, em média), receberia nota maior do que a mínima. Pensando no objetivo da geoconservação de resgatar áreas com decréscimo populacional, envelhecimento e êxodo rural, tais formulações não se sustentam.

Também merecem críticas os juízos de valor sobre a condição socioeconômica do entorno dos geomonumentos. Já no livro de Brilha (2005, p. 103), o critério B7 recomenda a nota 5 (máxima) para um geossítio localizado em áreas onde os níveis de rendimento per capita e de educação sejam maiores que a média nacional, e onde o desemprego seja menor. Por outro lado, a nota 1 (mínima) é atribuída a locais situados em áreas com indicadores socioeconômicos mais fracos que a média nacional. Essa elaboração, que pode ser considerada elitista, encontra eco nas metodologias propostas tanto por Lima et al. (2010) quanto por Pereira (2010), e se mantém também no cálculo do uso potencial turístico do trabalho de Brilha (2016), onde a nota 4 (máxima) é atribuída a geossítios situados em regiões com mais do que o dobro da renda familiar nacional. Compreendese que, do ponto de vista do turista e dos serviços potencialmente disponibilizados a este, áreas com níveis econômicos altos são mais atrativas. Essa, no entanto, é uma visão unilateral e, portanto, distorcida. Devem-se relembrar os objetivos primordiais da geoconservação, de resgatar áreas economicamente deprimidas e de paulatinamente reduzir, por intermédio do potencial turístico (que pode ainda não estar traduzido em infraestrutura ou serviços de qualidade), as desigualdades sociais, humanas e econômicas entre as diferentes regiões dentro de cada país. A priorização de geossítios em locais já detentores de bons indicadores econômicos pode, ao contrário, aprofundar essas 
desigualdades e impedir o resgate de áreas fragilizadas e marginalizadas pelos modelos econômicos vigentes.

A metodologia elaborada por Fassoulas et al. (2012), desenvolvida especialmente para áreas rurais montanhosas, de baixa densidade demográfica, da ilha de Creta (Grécia), parece ser a mais fiel aos princípios e ferramentas da geoconservação (conservação, turismo e educação), bem como a de mais imediata aplicabilidade a territórios rurais pouco povoados. Essa metodologia não faz juízos de valor sobre a densidade demográfica ou sobre as condições socioeconômicas do entorno dos geossítios, avaliando-os de forma mais equilibrada e completa em todos os seus aspectos. Sua aplicação, entretanto, necessita de uma equipe multidisciplinar, onde os aspectos geocientíficos, estéticos, ecológicos, culturais, legais, econômicos e de uso potencial de cada um dos geossítios sejam rigorosamente avaliados. Uma aplicação dessa metodologia foi publicada por Borba et al. (2013) para o geopatrimônio do município de Caçapava do Sul (RS), com uma adaptação relacionada ao número de visitantes (uma variável não disponível e, portanto, apenas estimada nos atrativos do interior gaúcho) e outra relacionada à supressão dos aspectos da formação da ética e da religiosidade humana, presentes entre os valores culturais da geodiversidade no contexto grego, mas ausentes no âmbito do interior do Rio Grande do Sul. Tais adaptações, entre tantos outros exemplos, ilustram também que nenhuma metodologia poderá ser utilizada de forma universal, sempre requerendo customizações dependentes do contexto natural ou social da área em estudo.

Em qualquer esforço de inventário e avaliação quantitativa de geossítios componentes do geopatrimônio, parece inevitável a sensação de se ter cometido injustiças ao aplicar uma metodologia uniforme a uma série de locais diferentes entre si e, por vezes, incomparáveis. Um caminho possível para a redução desse tipo de desequilíbrio é a elaboração de metodologias diferenciadas para cada tipologia de local de interesse geológico. Fuertes-Gutiérrez \& Fernández-Martínez (2010), por exemplo, já subdividem os geossítios em pontos, áreas simples, seções lineares, miradores e áreas complexas, o que já constitui um avanço importante. Sugere-se ainda um aprofundamento dessa subdivisão, no sentido de elaborar quantificações diferentes para: (a) afloramentos pontuais, onde os atributos científicos e educativos são preponderantes; (b) geoformas/elevações isoladas, nas quais o valor estético é decisivo; (c) grandes áreas de geomorfologia complexa, onde o valor funcional/ecológico se sobressai; (d) sítios 
paleontológicos; (e) miradores de observação da paisagem, onde a visibilidade desde o ponto de observação deve ser garantida; (f) quedas d'água, corredeiras, cascatas e cachoeiras, onde aspectos como altura, vazão de água e balneabilidade são decisivos; (g) seções de rios, zonas costeiras ou rodovias, onde as características estratigráficas se sobressaem; (h) sítios geológicos submarinos ou subaquáticos; e (i) sítios urbanos, onde a mobilidade urbana e os riscos relacionados à violência e ao trânsito devem ser considerados na avaliação. A elaboração de tais metodologias customizadas é uma interessante e promissora linha de pesquisa para o futuro da geoconservação. Tais metodologias poderiam, evidentemente, manter um mínimo de elementos em comum, que permitam realizar comparações intrínsecas (dentro de um mesmo território ou projeto, por exemplo), ensejando o estabelecimento de prioridades de uso e conservação.

\section{5 - Geoturismo e turismo geológico: conhecimento, diversão e responsabilidade socioambiental}

O termo geoturismo possui diversas acepções e interpretações. Em um primeiro momento, o geólogo britânico Hose (1995, p. 17) definiu geoturismo como a “(...) provisão de uma estrutura de serviços e interpretação que permita ao turista a aquisição de conhecimento e entendimento sobre a geologia e a geomorfologia de um local (...) além do nível da mera apreciação estética". A intenção, naquele momento, era a de incluir o conhecimento geológico nos programas turísticos já existentes, e recuperar o terreno perdido para a vertente do ecoturismo. Foi exatamente esse conceito que acabou por ser incorporado às estratégias de geoconservação e geoparques inauguradas a partir de então. Em outro contexto, no entanto, o geógrafo norte-americano Tourtellot (2006), da National Geographic Society, buscando uma oposição ao turismo de massa, oferece outra conceituação para geoturismo: o turismo que sustenta ou incrementa o caráter geográfico de um local, de seu meio ambiente, patrimônio, estética, cultura, bem como o bem-estar de seus residentes. Após quase uma década de incertezas sobre o uso da terminologia mais adequada, a Declaração de Arouca (AROUCA, 2011) estabeleceu um consenso: deixar o termo "geoturismo" para a conceituação norte-americana, apenas incluindo o vocábulo "geologia" àquela formulação, e tratar o conceito original europeu como "turismo geológico", constituindo apenas uma das vertentes do geoturismo. Ainda assim, a maior parte das estratégias do tipo geoparque continua utilizando o termo "geoturismo", inclusive o recente caderno institucional da UNESCO (2016). 
Independentemente da terminologia a ser utilizada, o importante é que o geoturismo tenha duas características primordiais: (a) seja efetivamente um turismo de conhecimento, além da mera contemplação e interação com a natureza, utilizando para isso meios de interpretação (TILDEN, 1957) aplicados ao geopatrimônio; e (b) oportunize, mediante o uso de técnicas interpretativas atraentes (e.g. MOREIRA, 2012; CARCAVILLA-URQUÍ, 2012), uma verdadeira viagem no tempo geológico, explorando a “quarta dimensão", ou seja, a evolução das rochas e do relevo ao longo dos milhares, milhões ou bilhões de anos da história da Terra, com necessária adaptação de linguagem. No entanto, pensar que tais programas (de turismo geológico em si) irão ter o potencial de atrair grande volume de visitantes parece um equívoco, especialmente nas regiões interioranas de um país com o nível de escolaridade e de amadurecimento cultural do Brasil. Por isso, sugere-se que os atrativos geoturísticos e o seu conteúdo sejam integrados, paulatina e progressivamente, em roteiros ou programas turísticos já existentes de outras modalidades sustentáveis, como o turismo rural, o ecoturismo, o turismo cultural e os esportes de aventura na natureza.

É importante, ainda, ter em mente que o geoturismo, apesar de ter o prefixo "geo", deve constituir sempre uma atividade de lazer, deleite, diversão. Visitas demoradas e recorrentes a uma série de museus ou laboratórios de pesquisa geológica/paleontológica (e.g. LORENCI, 2013), dentro de um mesmo programa turístico, só devem ser realizadas com públicos específicos e especializados, que manifestem tal intenção, sob pena de saturar os visitantes. Da mesma forma que não se deve oferecer aulas de geologia a turistas leigos, também não se pode considerar que alunos de disciplinas práticas de geologia ou geomorfologia estejam fazendo "turismo geológico" em suas saídas a campo, as quais fazem parte da carga-horária de seus cursos e constituem, portanto, uma atividade obrigatória, de trabalho. Evidentemente, fogem a essa restrição as atividades de turismo (seja geoturismo ou outra modalidade) feitas por grupos de estudantes em suas férias ou como excursão de lazer no final de seus cursos de educação básica.

A mais importante observação sobre o geoturismo, no entanto, refere-se a seu caráter local, preferencialmente desvinculado do aporte de capital financeiro externo e baseado em iniciativas da própria comunidade residente. Nesse sentido, o geoturismo deve se aproximar da perspectiva do turismo de base comunitária (TBC), ou seja, integrar-se socialmente, priorizar a geração de trabalho e renda, além de garantir a participação da 
comunidade no planejamento das atividades. Voltado para os interesses dos residentes, dos pequenos empreendimentos, da valorização e manutenção da identidade local, o TBC representa uma estratégia de desenvolvimento para grupos com menores condições de ingressarem de maneira autônoma na cadeia produtiva do turismo, buscando, nas palavras de Coriolano (2008, p. 43), "socializar as oportunidades", permitindo que o lucro do setor fique na comunidade. É uma forma de turismo que prioriza o lugar, a conservação ambiental e a identidade cultural (ARAÚJO e GELBCKE, 2008; CORIOLANO, 2012). É importante perceber que o TBC não se refere a uma nova modalidade de turismo, mas sim uma forma de pensar e planejar o turismo, seja em que modalidade for, a partir da comunidade (de baixo para cima, bottom-up), e jamais como uma imposição externa para a comunidade. Os moradores do lugar tornam-se os principais articuladores dessa cadeia produtiva, ao se sentirem capazes de planejar, organizar e explorar as atividades turísticas. Não se trata também de anular qualquer outra identidade ou atividade econômica já existente, mas de associar o turismo às demais atividades, inclusive com iniciativas que possam fortalecer a agricultura, a pecuária, o artesanato, entre outros. Essa característica de autenticidade e valorização do que é singular no território encontra eco também na já referida "Declaração de Arouca", que recomenda diretrizes para o geoturismo (AROUCA, 2011).

Na perspectiva de um geoturismo de base comunitária, a educação assume lugar de destaque, pois propicia o reconhecimento de valores culturais, sociais, ambientais e históricos; e demonstra que o lazer pode estar presente na troca de experiências, nas coisas simples e cotidianas, na interpretação da realidade (ARAÚJO e GELBCKE, 2008). Essa educação refere-se tanto ao anfitrião quanto ao visitante, principalmente no que diz respeito à conservação do patrimônio natural e/ou cultural. Para a comunidade local, esse processo de perceber e utilizar o patrimônio como recurso turístico estimula essas pessoas a cuidarem de maneira mais eficaz dos bens coletivos, de seus atrativos naturais/culturais e de suas paisagens.

\section{6 - Os geoparques/geoparks e o conceito geográfico de território}

Uma última reflexão crítica deve focalizar a utilização, no Brasil, do conceito de geoparque (no original, em inglês, geopark). Os trabalhos pioneiros sobre o assunto tratam essa estratégia de desenvolvimento como territórios povoados e de limites bem 
definidos, que combinem uma estratégia de desenvolvimento local sustentável com a proteção e promoção de um geopatrimônio singular, com apoio das autoridades locais (e.g. ZOUROS, 2004; McKEEVER e ZOUROS, 2005; HENRIQUES e BRILHA, 2017). A palavra-chave dessa conceituação é "território", uma das categorias de análise mais importantes da ciência geográfica, cujo significado deve ser compreendido também pelos pesquisadores e profissionais da geologia, no sentido de não se cometerem equívocos em sua aplicação. Ainda que haja muito debate dentro da própria geografia sobre territórios e territorialidades, cujo detalhamento não cabe aqui, reúnem-se duas elaborações interessantes para a presente discussão. Abramovay (1998), por exemplo, afirma que o território representa uma trama de relações com raízes históricas, configurações políticas e identidades. Em seus trabalhos, Haesbaert $(2004 ; 2007)$ ensina sobre a dualidade do território, que tanto pode relacionar-se à dominação (jurídico-política) da terra quanto, simbolicamente, inspirar a identificação (positiva) e a efetiva apropriação por aqueles que o usufruem.

O conceito de território, portanto, envolve poder e pertencimento: o poder refere-se à capacidade e ao direito de legislar, planejar (ordenar) e gerir sobre aquele recorte espacial; enquanto o pertencimento se refere à identificação da população com a natureza e a cultura do espaço socialmente transformado em território. Dessa forma, fica claro que os "territórios povoados e de limites bem definidos" de que trata o conceito de geoparque/geopark devem ser unidades territoriais histórica e politicamente estabelecidas, onde resida uma população que se identifique com esses limites. Geoparques, de acordo com a conceituação de território, podem ser municípios, conjuntos ou associações de municípios, ou ainda regiões administrativas com capacidade própria de gestão territorial. Não configuram territórios e, portanto, jamais poderão constituir geoparques, figuras como: (a) parques temáticos, parques geológicos ou empreendimentos turísticos; (b) meras listas de geossítios; (c) um conjunto de áreas isoladas entre si; (d) polígonos arbitrários desenhados sobre um mapa geológico; (e) contextos geológicos; ou (f) unidades de conservação onde não haja população humana residente.

O uso despreocupado dos termos território, região, área e zona, pelos profissionais da geologia, tem provocado confusão e incompreensões no processo de divulgação e popularização da estratégia dos geoparques no Brasil. Conforme discutido já por Borba 
(2017), muitos capítulos do volume "Geoparques do Brasil: propostas", editado por Schobbenhaus \& Silva (2012), trazem recortes espaciais que, confrontados ao conceito de território, não se sustentam. Tais recortes assemelham-se mais a poligonais de requerimento de lavra, áreas de estudo de trabalhos de conclusão de curso ou de mapeamento geológico básico, ou ainda simples figuras geométricas arbitrárias (ROCHA e PEDREIRA, 2012; THOMÉ FILHO et al., 2012; ROLIM e THEODOROWICZ, 2012; VIEIRA JÚNIOR et al., 2012). Essa falta de compreensão do conceito de território pode estar entre as principais razões para que, até o momento, o Brasil, com suas dimensões continentais e sua geologia altamente diversificada e interessante, tenha apenas um geoparque certificado pela rede mundial de geoparques (GGN) e pela UNESCO. O Geopark Araripe, aliás, detentor do certificado, constitui um verdadeiro território, englobando um conjunto de seis municípios do sul do Estado do Ceará, reunidos em torno de uma estratégia de desenvolvimento e valorização do geopatrimônio, especialmente aquele de cunho paleontológico.

Por fim, deve-se ressaltar que, na visão dos autores do presente trabalho, a designação de um território como geoparque/geopark consiste em uma certificação e, portanto, um reconhecimento para uma situação já existente que inclua, no mínimo: (1) conhecimento e valorização da geodiversidade pela comunidade acadêmica e pelos habitantes locais; (2) inventário do geopatrimônio; (3) proteção legal dos locais de interesse geopatrimonial mais relevantes; e (4) iniciativas de geoturismo e geoeducação em curso. Portanto, qualquer estratégia de geoconservação deve iniciar-se pelos levantamentos básicos, pelo contato com as comunidades locais, pela integração com as escolas locais e instituições (públicas e/ou privadas) de turismo, e por iniciativas de geoconservação altruístas e de baixo custo. Ao final dessa caminhada, se for interessante para a comunidade e para o território em questão, pode-se pleitear uma certificação como geoparque da UNESCO, com boas chances de sucesso. Por outro lado, projetos que iniciaram já com foco na certificação (e inclusive com o nome geoparque/geopark desde o princípio), como o Quadrilátero Ferrífero (RUCHKYS, 2007), ou com decretos governamentais de criação a priori, como o Bodoquena-Pantanal, no Mato Grosso do Sul (e.g. ROLIM e THEODOROWICZ, 2012), têm enfrentado muitas dificuldades para a efetiva obtenção do selo da UNESCO, sendo obrigados a reformular suas estratégias e, inclusive, seus recortes territoriais. 


\section{7 - Considerações finais}

As deficiências, inconsistências e incoerências da teoria e da prática da pesquisa em geopatrimônio e das iniciativas em geoconservação, no Brasil e no mundo, levantadas ao longo deste trabalho, devem constituir o foco de novas reflexões e debates por parte dos profissionais e pesquisadores da área. Reforça-se, aqui, a necessidade premente de que a ciência geográfica contribua muito mais com os estudos de geoconservação, não no sentido de modificar seu objeto (materiais, feições e histórias evolutivas geológicas e geomorfológicas), mas sim para redirecionar a abordagem, tornando a geoconservação mais humana, mais interpretativa e mais próxima da sociedade, da escola e da conservação ambiental. Metodologias para o inventário e a avaliação quantitativa de locais de interesse geopatrimonial devem considerar muito mais do que apenas o valor geocientífico, sob pena de um isolamento cada vez maior da geologia e da geomorfologia em relação a outras áreas do conhecimento e, sobretudo, à sociedade leiga. Nesse sentido, valores culturais, estéticos, funcionais/ecológicos e funcionais/utilitários são tão relevantes para a atribuição de um caráter patrimonial a uma ocorrência da geodiversidade quanto sua importância para os geocientistas e para o meio acadêmico. Da mesma forma, as avaliações do geopatrimônio não podem ser elitistas, não devem se curvar aos interesses do setor mineral, e nem priorizar a proximidade a centros urbanos, uma vez que a filosofia basilar da geoconservação e do geoturismo/turismo geológico contempla, exatamente, o resgate de áreas rurais marginalizadas e a redução das desigualdades regionais. A geoconservação, o geoturismo, a geoeducação e os geoparques possuem um grande potencial para se tornarem estratégias eficazes e socialmente reconhecidas de popularização do conhecimento e, ao mesmo tempo, de desenvolvimento endógeno, sustentável e de base local. Para isso, no entanto, é necessário assumir-se uma posição firme no sentido de uma atuação social e ambientalmente responsável, desde a pesquisa básica até as ações de divulgação e promoção do geopatrimônio junto à sociedade. 


\section{REFERÊNCIAS}

ABRAMOVAY, Ricardo. Bases para a formulação da política brasileira de desenvolvimento rural: agricultura familiar e desenvolvimento territorial. Brasília, IPEA, 1998, 25p.

ARAÚJO, Guilherme P. de; GELBCKE, Daniele Lima. Turismo Comunitário: uma perspectiva ética e educativa de desenvolvimento. Revista Turismo Visão e Açãa Eletrônica, v. 10, n. 3, p. 357-378, 2008.

AROUCA, 2011. Declaração de Arouca, 2011. Disponível em https://www.azoresgeopark.com/media/docs/declaracao_de_arouca_geoturismo.pdf, consulta em 19/06/2018.

BERTRAND, G. Paisagem e geografia física global: esboço metodológico. São Paulo: USP, 1972.

BORBA, André Weissheimer de. Geodiversidade e geopatrimônio como bases para estratégias de geoconservação: conceitos, abordagens, métodos de avaliação e aplicabilidade no contexto do Estado do Rio Grande do Sul. Pesquisas em Geociências, v. 38, n. 1, p. 3-13, 2011.

BORBA, André Weissheimer de. Um geopark na região de Caçapava do Sul (RS, Brasil): uma discussão sobre viabilidade e abrangência territorial. Geographia Meridionalis, v. 3, n. 1, p. 104-133, 2017.

BORBA, André Weissheimer de; SOUZA, Luiz Fernando de; MIZUSAKI, Ana Maria Pimentel; ALMEIDA, Delia del Pilar Montecinos de; STUMPF, Paola Prates. Inventário e avaliação quantitativa de geossítios: exemplo de aplicação ao patrimônio geológico do município de Caçapava do Sul (RS, Brasil). Pesquisas em Geociências, v. 40, n. 3, p. 275-294, 2013.

BRILHA, José Bernardo Rodrigues. A geologia, os geólogos e o manto da invisibilidade. Comunicação e Sociedade, v. 6, p. 257-265, 2004.

BRILHA, José Bernardo Rodrigues. Património geológico e geoconservação: a conservação da natureza na sua vertente geológica. Viseu: Palimage Editores, 2005, $190 \mathrm{p}$.

BRILHA, José Bernardo Rodrigues. Inventory and quantitative assessment of geosites and geodiversity sites: a review. Geoheritage, v. 8, n. 2, p. 119-134, 2016.

CARCAVILLA-URQUÍ, Luís. Geoconservación: un recorrido por lugares geológicos excepcionales para entender cómo y por qué debemos protegerlos. Madrid, IGME y Los Libros de la Catarata, 2012, 126p.

CENDRERO-UCEDA, Antonio. Patrimonio geológico: diagnóstico, clasificación y valoración. In: SUÁREZ-VALGRANDE, J. Palacio (Ed.) Jornadas sobre Patrimonio Geológico y Desarrollo Sostenible. Serie Monografias, Ministerio del Medio Ambiente, España, 2000, p. 23-37. 
CORIOLANO, Luzia Neide Menezes Teixeira. O turismo comunitário no nordeste brasileiro. In: V Seminário da Associação Nacional de Pesquisa e Pós-Graduação em Turismo, Resumos... Belo Horizonte. 2008.

CORIOLANO, Luzia Neide Menezes Teixeira. A contribuição do turismo ao desenvolvimento local. In: PORTUGUEZ, Anderson Pereira; SEABRA, Giovanni de Farias; QUEIROZ, Odaléia Telles M. M. (Orgs.) Turismo, Espaço e Estratégias de Desenvolvimento local. Editora Universitária UFPB, João Pessoa, 2012.

FASSOULAS, Charalambos; MOURIKI, Dimitra; DIMITRIOU-NIKOLAKIS, Panagiotis; ILIOPOULOS, George. Quantitative assessment of geotopes as an effective tool for geoheritage management. Geoheritage, v. 4, n. 3, p. 177-193, 2012.

FUERTES-GUTIÉRREZ, Inés; FERNÁNDEZ-MARTÍNEZ, Esperanza. Geosites inventory in the Leon Province (Northwestern Spain): a tool to introduce geoheritage into regional environmental management. Geoheritage, v. 2, p. 57-75, 2010.

GRAY, Murray. Geodiversity: valuing and conserving abiotic nature. Wiley, Chichester, 2004, 448p.

GRAY, Murray. Geodiversity: developing the paradigm. Proceedings of the Geologists' Association, v. 119, p. 287-298, 2008.

HAESBAERT, Rogério. O mito da desterritorialização: do "fim dos territórios" à multiterritorialidade. Rio de Janeiro, Bertrand Brasil, 2004, 395p.

HAESBAERT, Rogério. Território e multiterritorialidade: um debate. Geographia, v. 9, n. 17, p. 19-45, 2007.

HENRIQUES, Maria Helena; PENA-DOS-REIS, Rui; BRILHA, José Bernardo Rodrigues; MOTA, Teresa. Geoconservation as an emerging geoscience. Geoheritage, v. 3, n. 2, p. 117-128, 2011.

HENRIQUES, Maria Helena; BRILHA, José Bernardo Rodrigues. UNESCO Global Geoparks: strategy towards global understanding and sustainability. Episodes, v. 40, n. 4, p. 349-355, 2017.

HOSE, Thomas A. Selling the story of Britain's stone. Environmental Interpretation, v. 2, p. 16-17, 1995.

LIMA, Flávia Fernanda de; BRILHA José Bernardo Rodrigues; SALAMUNI Eduardo. Inventorying geological heritage in large territories: a methodological proposal applied to Brazil. Geoheritage, v. 2, p. 91-99, 2010.

LOPES, Larissa Sheydder Oliveira; ARAÚJO, J.L.L. Princípios e estratégias de geoconservação. Observatorium: Revista Eletrônica de Geografia, v. 3, n. 7, p. 66-78, 2011. 
LORENCI, Carmen Terezinha Barcellos. Geoturismo: uma ferramenta auxiliar na interpretação e preservação do patrimônio geopaleontológico da região central do Rio Grande do Sul. Universidade Federal de Santa Maria, Programa de Pós-Graduação Profissionalizante em Patrimônio Cultural, Dissertação de Mestrado, 2013, 183p.

MAKSOUD, Kholoud Mohamed Abdel; EL-SHAFEIY, Moataz Adel; RASHED Tamer Gad. Geo-education in Egypt, ideas, challenges and vision. International Journal of Educational Policy Research and Review, v. 1, n. 2, p. 014-020, 2014.

MANTESSO-NETO, Virgínio. Geologia e Conservacionismo: uma associação urgentemente necessária. In: Congresso Brasileiro de Geologia, 45, Belém/PA, 2010. Apresentação oral. Disponível em https://pt.scribd.com/doc/302094489/Geologia-eConservacionismo-45\%C2\%BA-CBG-Mantesso-Neto-2010, acesso em 9/11/2016.

McKEEVER, Patrick J.; ZOUROS, Nickolas. Geoparks: celebrating Earth heritage, sustaining local communities. Episodes, v. 28, n. 4, p. 274-278, 2005.

MOREIRA, Jasmine Cardozo. Interpretative Panels About the Geological Heritage - a Case Study at the Iguassu Falls National Park (Brazil). Geoheritage, v. 4, p. 127-137, 2012.

MOURA-FÉ, Marcelo Martins de. GeoPark Araripe e a geodiversidade do sul do Estado do Ceará, Brasil. Revista de Geociências do Nordeste - REGNE, v. 2, n. 1, p. 28-37, 2016.

MUCIVUNA, Vanessa Costa; GARCIA, Maria da Glória Motta; DEL LAMA, Eliane A. Inventário e avaliação quantitativa do patrimônio geológico de Bertioga (SP, Brasil). Pesquisas em Geociências, v. 44, n. 2, p. 293-321, 2017.

PAIM, Paulo Sérgio Gomes; CHEMALE JR., Farid; LOPES, Ricardo Cunha. A Bacia do Camaquã. In: HOLZ, Michael; DE ROS, Luiz Fernando (Eds.) Geologia do Rio Grande do Sul, Porto Alegre, Edições CIGO/UFRGS, 2000, p. 231-274.

PANIZZA, Mario. The geomorphodiversity of the Dolomites (Italy): a key to geoheritage assessment. Geoheritage, v. 1, p. 33-42, 2009.

PENA-DOS-REIS, Rui; HENRIQUES, Maria Helena. Approaching an integrated qualification and evaluation system for geological heritage. Geoheritage, v. 1, p. 1-10, 2009.

PEREIRA, Ricardo Galeno Fraga de Araújo. Geoconservação e Desenvolvimento Sustentável na Chapada Diamantina (Bahia - Brasil). Escola de Ciências, Universidade do Minho, Braga, Tese de Doutorado, 2010, 318p.

REVERTE, Fernanda Coyado; GARCIA, Maria da Glória Motta. Avaliação quantitativa do patrimônio geológico: aplicação aos geossítios de São Sebastião, litoral norte do Estado de São Paulo. Anuário do Instituto de Geociências, v. 39, n. 2, p. 43-56, 2016. 
ROCHA, Antonio José Dourado; PEDREIRA, Augusto. Geoparque Morro do Chapéu (BA) - proposta. In: SCHOBBENHAUS, Carlos; SILVA, Cássio Roberto (Orgs.) Geoparques do Brasil - Propostas, CPRM, 2012, p. 59-110.

ROCHA, Antonio José Dourado; LIMA, E., SCHOBBENHAUS, Carlos. Aplicativo GEOSSIT - nova versão. In: XLVIII Congresso Brasileiro de Geologia, Porto Alegre, $2016 . \quad$ Disponível em: http://sbg.sitepessoal.com/anais48cbg/st22/ID6389_111446_52_Aplicativo_Geossit.pdf , acesso em 22 de novembro de 2016.

RODRIGUES, Maria Luísa; FONSECA, André. 2008. A valorização do geopatrimónio no desenvolvimento sustentável de áreas rurais. In: COLÓQUIO IBÉRICO DE ESTUDOS RURAIS (CIER), 7, Actas..., Coimbra, Portugal.

ROLIM, Fabio Guimarães; THEODOROWICZ, Antonio. Geoparque BodoquenaPantanal - proposta. In: SCHOBBENHAUS, Carlos; SILVA, Cássio Roberto (Orgs.) Geoparques do Brasil - Propostas, CPRM, 2012, p. 221-282.

ROMERO, A.G.; JIMÉNEZ, J.M. El Paisaje en el Ámbito de la Geografia. Cidade do México: UNAM, 2002.

RUBAN, Dmitry A. Quantification of geodiversity and its loss. Proceedings of the Geologists' Association, v. 121, p. 326-333, 2010.

RUCHKYS Ursula A. Patrimônio geológico e geoconservação no Quadrilátero Ferrífero, Minas Gerais: potencial para a criação de um geoparque da UNESCO. Universidade Federal de Minas Gerais, Tese de Doutorado, 2007, 211p.

SCHOBBENHAUS, Carlos; SILVA, Cássio Roberto. Geoparques do Brasil Propostas. Rio de Janeiro, CPRM, 2012, 748p, 2012.

SHARPLES, Chris. Concepts and principles of geoconservation. Tasmanian Parks and Wildlife Service, electronic publication, 2002, 81p.

SOTCHAVA, V. B. Estudo de Geossistemas. Métodos em Questão n ${ }^{\circ}$ 6. São Paulo: IG, USP, 1977.

STANLEY, Mick. Geodiversity. Earth Heritage, v. 14, p. 15-18, 2000.

THOMÉ FILHO, Jamilo José; CRÓSTA, Álvaro Penteado; PAULA, Thiago Luiz Feijó de. Geoparque Astroblema de Araguainha-Ponte Branca (GO/MT) - proposta. In: SCHOBBENHAUS, Carlos; SILVA, Cássio Roberto (Orgs.) Geoparques do Brasil Propostas, CPRM, 2012, p. 151-182.

TILDEN, Freeman. Interpreting our heritage. The University of North Carolina Press, Chapell Hill, 1957, 142 p.

TOURTELLOT, Jonathan B. Geotourism for your community: a guide for a geotourism strategy. Center for Sustainable Destinations, National Geographic Society, Washington, 2006, 24p. 
UNESCO. UNESCO Global Geoparks Brochure, 20p., 2016. Disponível em http://unesdoc.unesco.org/images/0024/002436/243650e.pdf, acesso em 22 de julho de 2016.

VIEIRA JÚNIOR, Hamilcar Tavares; MORAES, Juliana Maceira; PAULA, Thiago Luiz Feijó de. Geoparque Chapada dos Guimarães (MT) - proposta. In: SCHOBBENHAUS, Carlos; SILVA, Cássio Roberto (Orgs.) Geoparques do Brasil - Propostas, CPRM, 2012, p. 283-316.

ZOUROS, Nickolas. The European Geoparks Network: geological heritage protection and local development. Episodes, v. 27, n. 3, p. 165-171, 2004. 